\title{
Coagulation in Chronic Urticaria
}

Riccardo Asero, $M D^{1, *}$

Alberto Tedeschi, $M D^{2}$

Angelo Valerio Marzano, $M D^{3}$

Massimo Cugno, $M D^{4}$

\author{
Address \\ ${ }^{*}, 1$ Ambulatorio di Allergologia, Clinica San Carlo, Via Ospedale 21, 20037, Paderno \\ Dugnano, MI, Italy \\ Email: r.asero@libero.it \\ ${ }^{2}$ U.0. Allergologia e Immunologia Clinica, Fondazione IRCCS Ca' Granda, Ospedale \\ Maggiore Policlinico, Milano, Italy \\ ${ }^{3}$ Unità Operativa di Dermatologia, Fondazione IRCCS Ca' Granda, Ospedale \\ Maggiore Policlinico, Dipartimento di Fisiopatologia Medico-Chirurgica e dei \\ Trapianti, Università degli Studi di Milano, Milano, Italy \\ ${ }^{4}$ Medicina Interna, Dipartimento di Fisiopatologia Medico-Chirurgica e dei \\ Trapianti, Università degli Studi di Milano, IRCCS Fondazione Ca' Granda, Ospedale \\ Maggiore Policlinico, Milano, Italy
}

Published online: 20 0ctober 2015

(C) Springer International Publishing AG 2015

This article is part of the Topical Collection on Urticaria and Atopic Dermatitis

Keywords Chronic urticaria · Coagulation · Thrombin · Tissue Factor · Eosinophils · Heparin · Oral anticoagulants

\section{Opinion statement}

There is increasing evidence that the coagulation cascade may play a role in the pathophysiology of chronic urticaria, particularly in severely active forms. Although anticoagulant therapy is presently not included among the standard treatments of severe chronic urticaria, based on the limited, but encouraging, literature presently available either warfarin or heparin could be considered as an add-on therapy in severely affected patients that do not respond to either antihistamines, omalizumab or ciclosporin, showing elevated plasma levels of D-dimer.

\section{Introduction}

Chronic spontaneous urticaria (CSU) is a relatively frequent disease, affecting up to $1 \%$ of the general population at some point in life. It is characterized by recurrent or persistent itch, wheals and in about one half of cases also by angioedema for more than 6 weeks. In severe cases, it may become a heavily disturbing problem that markedly worsens the quality of life of patients. The disease is caused by the release of histamine from mast cells and basophils with the contribution of other biologically active substances including platelet activating factor, neuropeptides, arachidonic acid metabolites such as PGD2, LTC4, LTD4, and LTE4, 
and serotonin. The anaphylatoxins C3a and C5a may also play a role in the pathogenesis. These substances contribute to the appearance of erythema, wheals, and itch by inducing vasodilation, increasing vascular permeability, and stimulating sensory nerve endings [1]. Autoimmune mechanisms, particularly IgG autoantibodies specific for the high affinity IgE receptor, FceRI, or for IgE [2,3] may also participate to the pathogenesis of the disease in a proportion of patients (about 40-50 \%). In recent years, the coagulation cascade activation has added to this already complex pathogenic picture. The present review will examine the current knowledge on this topic and discuss possible alternative treatments for patients not responding to standard therapies

\section{Coagulation and Chronic Urticaria (Fig. 1)}

In recent years, a relevant piece of evidence has appeared in the medical literature suggesting that the coagulation cascade might be involved in the pathophysiology of chronic spontaneous urticaria [4-8]. The first observations in this sense, published in 2006, noted that chronic urticaria is associated with elevated plasma levels of prothrombin fragment $\mathrm{F} 1+2$, a marker of thrombin generation, and that such levels parallel the disease severity [9]. Subsequent studies found that thrombin generation is associated with the activation of the extrinsic pathway of coagulation as shown by increased plasma levels of activated factor VII (FVIIa) [10]. In patients with severe urticaria, the activation of the coagulation cascade may be intense enough to lead to fibrinolysis, as shown by an increase in plasma levels of Ddimer paralleling disease severity [11]. In keeping with the findings by Moosbauer et al. [12] showing that eosinophils are a major intravascular source of tissue factor, Cugno et al. were able to demonstrate that eosinophils are the main cells expressing TF in chronic urticaria [13]. What initiates the activation of eosinophils is still unclear. One study was able to show the presence of circulating autoantibodies to FceRII, the low affinity IgE receptor [14], in about $70 \%$ of CU patients. The major basic protein (MBP), released by the eosinophils activated by such autoantibodies, would cause mast cell degranulation [14]. Interestingly, eosinophils might be in turn activated and recruited by mediators, cytokines,

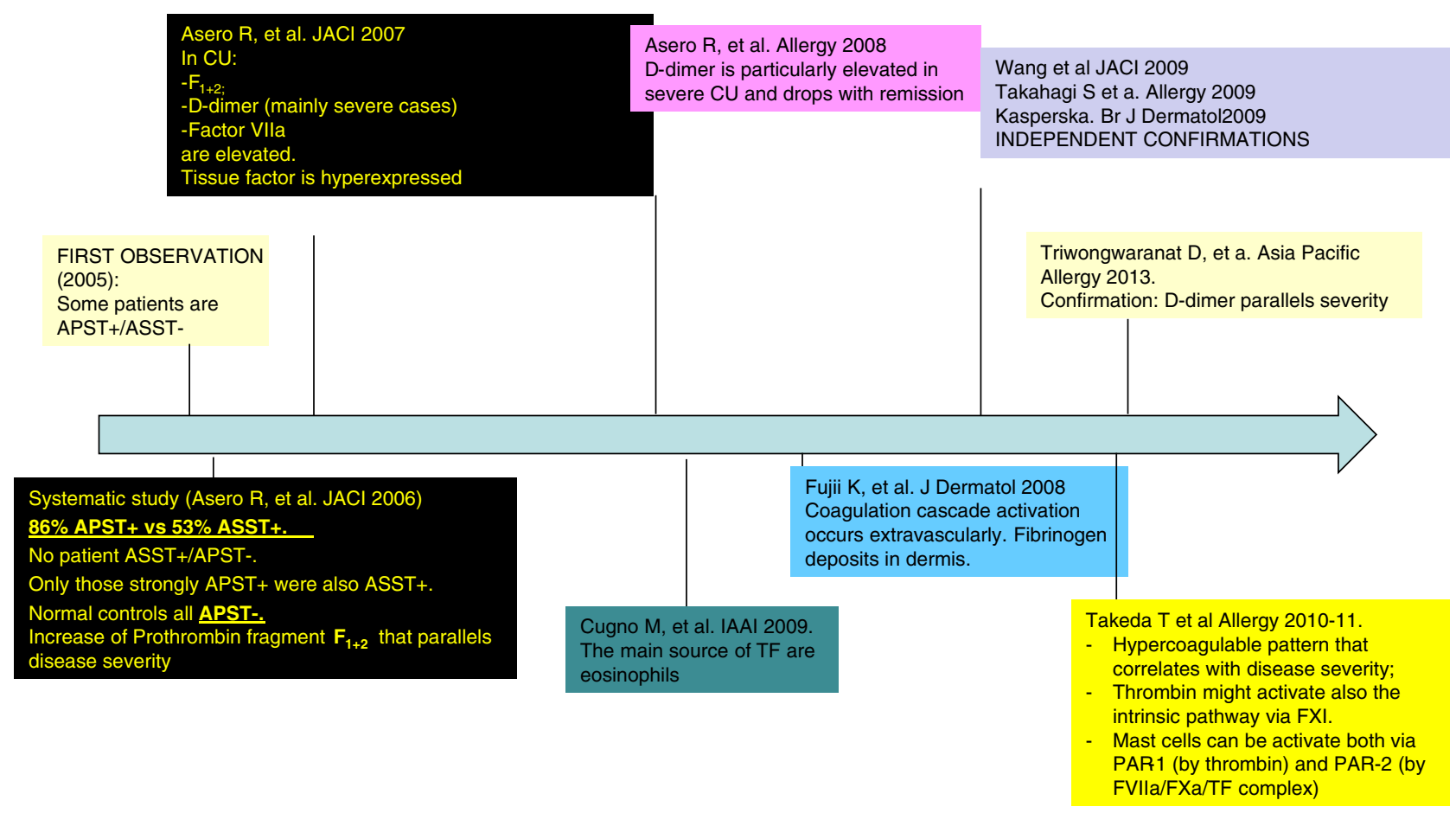

Fig. 1. History of the main studies of coagulation in chronic spontaneous urticaria. 
chemokines, or other as yet unknown factors released by mast cells [15-18]. The findings summarized above have been confirmed by several independent groups [19-26].

Thus, it seems likely that coagulation may play a role in the pathogenesis of chronic urticaria. In animal models, thrombin induces $\mathrm{MC}$ degranulation with potency similar to that of FceRI-mediated activation [27]. Mast cell activation by coagulation factors occurs via the so-called protease-activated receptors 1 and 2 (PAR- 1 and PAR-2). Thrombin is able to activate the mast cell via PAR-1, while TF+factor VIIa (FVIIa) and factor Va (FVa)+factor Xa (FXa) complexes act via PAR-2 $[28,29]$. The activation of PAR1 and/or PAR-2 receptors leads to mast cell degranulation. In turn, tryptase released by mast cells is able to activate directly prothrombin, thus generating thrombin [30], and giving rise to an amplification loop. Further, thrombin may increase vascular permeability by a direct effect on endothelial cells [29-33] and can activate $\mathrm{C} 5$ to $\mathrm{C} 5 \mathrm{a}$ in the absence of $\mathrm{C} 3$, thus bypassing the first stage of the complement cascade [34]. The increased levels of activated complement component 5 (C5a) in patients with active CU support the possible involvement of complement system in the pathophysiology of the disease [24]. The activation of the coagulation cascade correlates with disease severity in all studies carried out so far, and plasma levels of commonly measurable factors drop during the remission phases.

\section{Coagulation Cascade Activation and Inflammation}

Active CU is characterized by a perivascular, nonnecrotizing infiltrate of Th1 and Th2 lymphocytes, monocytes, neutrophils, eosinophils, and basophils $[35,36]$, and by a systemic inflammatory process, as shown by the frequent increase in circulating $\mathrm{C}$ reactive protein (CRP), interleukin-6 (IL-6), and matrix metalloprotease 9 (MMP-9) [37, 38]. Immune response, inflammation, and coagulation [39, 40] are closely linked to each other. The expression of tissue factor (TF), the main initiator of blood coagulation, is induced by pro-inflammatory cytokines such as IL6 and tumor necrosis factor alpha (TNF- $\alpha$ ) [40]. Proteases, such as several activated coagulation factors, are able to induce the expression of inflammatory cytokines by activating protease-activated receptors (PARs) present on effector cells [41]. Thus, coagulation and inflammation are able to activate each other increasing their respective effects.

\section{D-Dimer as Predictor of Response to Treatment}

Recent studies show that the elevated plasma levels of Ddimer, although not specific for chronic urticaria (as they can be observed in a number of other inflammatory processes) may be used as a biomarker of a severe disease that is often resistant to antihistamine treatment $[11,42 \bullet, 43]$, and sometimes to ciclosporin as well $[44 \bullet]$.

\section{Is There Thrombophilia in Chronic Spontaneous Urticaria?}

Although, theoretically, the hypercoagulation state that characterizes CSU might be associated with an increased risk of thrombosis, no increased incidence of thrombotic events has been reported so far. This might be due in part not only to the presence of an efficient thombolytic system but also to a predominant extravascular location of fibrin deposition, suggesting that the coagulation cascade observed in CSU occurs extravascularly [21]. It has been suggested that patients with long-term CSU, accompanied by systemic inflammation, particularly with raised blood levels of CRP, may have an increased risk of cardiovascular disorders [45] although other observations indicated that the hypercoagulation occurring in CSU and AE is unlikely to be associated with an increased risk of thrombosis, in contrast to patients with acute urticaria [8] or with other skin diseases such as bullous pemphigoid [46].

\section{Anticoagulants/Antifibrinolytics in Chronic Spontaneous Urticaria}

Although the exact role of the activation of coagulation/ fibrinolysis in the pathogenesis of CSU has still to be defined, the fact that such an activation parallels the activity of the disease $[11,47]$ provides theoretically a rationale to test effects of anticoagulant and antifibrinolytic therapy in patients with severe forms. A small double-blind, placebo-controlled study carried out about 15 years ago first detected the effectiveness of oral anticoagulant therapy in some patients with refractory CSU [48]. After an attempt carried out more than 60 years ago [49], in some more recent studies, heparin also has been effective in patients with severe disease [50,51] and elevated D-dimer plasma levels [52]. In the first study [50], a 43-year-old woman with antihistamine-resistant chronic urticaria responded well to heparin therapy. In the second one [51], a 59-year-old woman who had been suffering from CSU for 7 years was successfully treated first with nadroparin and then with acenocoumarol which has been given due to an 
intercurrent deep vein thrombosis. Finally, in the latter study, nadroparin (11,400 IU per day) and tranexamic acid (given orally $1 \mathrm{~g}$ three times a day for 2 weeks), given as an add-on therapy in patients under H1antihistamine treatment, induced a significant decrease in disease symptoms in five of eight patients [52]. In contrast, tranexamic acid given alone has produced less convincing results; in fact, a reduction in the frequency of CSU attacks was reported in two patients [53], whereas no significant differences were found between tranexamic acid and placebo treatment in a double-blind study performed in 17 patients [54]. Two other serine protease inhibitors effective on coagulation and fibrinolysis, named nafamostat mesilate and camostat mesilate, were shown to improve symptoms in two patients with refractory CSU [55]. Interestingly, these drugs inhibit different proteases, including tryptase, kallikrein, complement, factor XII, and plasmin, and show an anticoagulant effect similar to that of heparin [56].

\section{Conclusions}

There is increasing evidence that the coagulation cascade has the potential to play a role in the pathogenesis of chronic spontaneous urticaria, particularly in severe cases. Scattered reports of the efficacy of drugs interfering at different levels with the activation of this system indirectly support such concept. It is well known that about one fourth of patients with severe, antihistamine-resistant, chronic urticaria do not respond to second-level treatments such as omalizumab or ciclosporin. While data in patients not responding to omalizumab are missing, it is quite clear that in ciclosporin-resistant patients, the coagulation cascade is heavily activated [44•]. Interestingly, effective omalizumab treatment is associated with a decrease in D-dimer levels in patients with chronic urticaria [57•]. The future studies should investigate whether the adjunct of an anticoagulant (either warfarin or heparin) to omalizumab or ciclosporin leads to a better control of the disease in patients not responding to these drugs.

\section{Compliance with Ethics Guidelines}

\section{Conflict of Interest}

Riccardo Asero declares that he has no conflict of interest.

Alberto Tedeschi declares that he has no conflict of interest.

Angelo Valerio Marzano declares that he has no conflict of interest.

Massimo Cugno declares that he has no conflict of interest.

Human and Animal Rights and Informed Consent

This article does not contain any studies with human or animal subjects performed by the authors. 


\section{References and Recommended Reading}

Papers of particular interest, published recently, have been highlighted as being:

- Of importance

1. Hein R. Chronic urticaria: impact of allergic inflammation. Allergy. 2002;57:S19-24.

2. Gruber B, Baeza M, Marchese M, Agnello V, Kaplan AP. Prevalence and functional role of anti-IgE autoantibodies in urticarial syndromes. J Invest Dermatol. 1988;90:213-7.

3. Grattan C, Sabroe R, Greaves M. Chronic urticaria. J Am Acad Dermatol. 2002;46:645-57.

4. Cugno M, Marzano AV, Asero R, Tedeschi A. Activation of blood coagulation in chronic urticaria: pathophysiological and clinical implications. Intern Emerg Med. 2009;5:97-101.

5. Asero R, Riboldi P, Tedeschi A, Cugno M, Meroni P. Chronic urticaria: a disease at a crossroad between autoimmunity and coagulation. Autoimmun Rev. 2007;7:71-6.

6. Cugno M, Tedeschi A, Crosti C, Marzano AV. Activation of blood coagulation in autoimmune skin disorders. Expert Rev Clin Immunol. 2009;5:605-13.

7. Cugno M, Tedeschi A, Asero R, Meroni PL, Marzano AV. Skin autoimmunity and blood coagulation. Autoimmunity. 2010;43:189-94.

8. Cugno M, Asero R, Tedeschi A, Lazzari R, Marzano AV. Inflammation and coagulation in urticaria and angioedema. Curr Vasc Pharmacol. 2012;10:653-8.

9. Asero R, Tedeschi A, Riboldi P, Cugno M. Plasma of patients with chronic urticaria shows signs of thrombin generation, and its intradermal injection causes whealand-flare reactions much more frequently than autologous serum. J Allergy Clin Immunol. 2006;117:11137.

10. Asero R, Tedeschi A, Coppola R, et al. Activation of the tissue factor pathway of blood coagulation in patients with chronic urticaria. J Allergy Clin Immunol. 2007;119:705-10.

11. Asero R, Tedeschi A, Riboldi P, Griffini S, Bonanni E, Cugno M. Severe chronic urticaria is associated with elevated plasma levels of D-dimer. Allergy. 2008;63:176-80.

12. Moosbauer C, Morgenstern E, Cuvelier SL, Manukyan D, Bidzhekov K, Albrecht S, et al. Eosinophils are a major intravascular location for tissue factor storage and exposure. Blood. 2007;109:995-1002.

13. Cugno M, Marzano AV, Tedeschi A, Fanoni D, Venegoni L, Asero R. Expression of tissue factor by eosinophils in patients with chronic urticaria. Int Arch Allergy Clin Immunol. 2009;148:170-4.

14. Puccetti A, Bason C, Simeoni ME, Tinazzi E, Beri R, Peterlana $\mathrm{D}$, et al. In chronic idiopathic urticaria autoantibodies against Fc epsilonRII/CD23 induce histamine release via eosinophil activation. Clin Exp Allergy. 2005;35:1599-607.

15. Asero R, Cugno M, Tedeschi A. Eosinophils in chronic urticaria: supporting or leading actors? World Allergy Organ J. 2009;2:213-7.

16. Shakoory B, Fitzgerald SM, Lee SA, Chi DS, Krishnaswamy G. The role of human mast cell-derived cytokines in eosinophil biology. J Interferon Cytokine Res. 2004;24:271-81.

17. Lampinen $M$, Carlson $M$, Hakansson LD, Venge P. Cytokine-regulated accumulation of eosinophils in inflammatory disease. Allergy. 2004;59:793-805.

18. Tedeschi A, Asero R, Lorini M, Marzano AV, Cugno M. Serum eotaxin levels in patients with chronic spontaneous urticaria. Eur Ann Allergy Clin Immunol. 2012;44:188-92.

19. Wang F, Tang H, Xu JH, Kang KF. Activation of the blood coagulation cascade is involved in patients with chronic urticaria. J Allergy Clin Immunol. 2009;123:972-3.

20. Takeda T, Sakurai Y, Takahagi S, Kato J, Yoshida K, Yoshioka A, et al. Increase of coagulation potential in chronic spontaneous urticaria. Allergy. 2011;66:42833.

21. Fujii K, Usuki A, Kan-No Y, Ohgou N. Elevation of circulating thrombin-antithrombin III complex and fibrin degradation products in urticaria. A laboratory finding unrelated to intravascular coagulopathy. J Dermatol. 2008;35:308-10.

22. Khalaf AT, Liu XM, Sheng WX, Tan JQ, Abdalla A. Efficacy and safety of desloratadine combined with dipyridamole in the treatment of chronic urticaria. J Eur Acad Dermatol Venereol. 2008;22:487-92.

23. Yildiz H, Karabudak O, Dogan B, Harmanyeri Y. Evaluation of autologous plasma skin test in patients with chronic idiopathic urticaria. Br J Dermatol. 2011;165:1205-9.

24. Zhu H, Liang B, Li R, Li J, Lin L, Ma S, et al. Activation of coagulation, anti-coagulation, fibrinolysis and the complement system in patients with urticaria. Asian Pac J Allergy Immunol. 2013;31:43-50. 
25. Criado PR, Antinori LC, Maruta CW, Reis VM. Evaluation of D-dimer serum levels among patients with chronic urticaria, psoriasis and urticarial vasculitis. An Bras Dermatol. 2013;88:355-60.

26. Triwongwaranat D, Kulthanan K, Chularojanamontri L, Pinkaew S. Correlation between plasma D-dimer levels and the severity of patients with chronic urticaria. Asia Pac Allergy. 2013;3:100-5.

27. Razin E, Marx G. Thrombin-induced degranulation of cultured bone marrow-derived mast cells. J Immunol. 1984;133:3282-5.

28. Dugina TN, Kiseleva EV, Chistov IV, Umarova BA, Strukova SM. Receptors of the PAR family as a link between blood coagulation and inflammation. Biochem Mosc. 2002;67:65-74.

29. Ossovskaya VS, Bunnett NW. Protease-activated receptors: contribution to physiology and disease. Physiol Rev. 2004;84:579-621.

30. Kido H, Fukusen N, Katunuma M, Morita T, Iwanaga S. Tryptase from rat mast cells converts bovine prothrombin to thrombin. Biochem Biophys Res Commun. 1985;132:613-9.

31. DeMichele MA, Moon DG, Fenton 2nd JW, Minnear FL. Thrombin's enzymatic activity increases permeability of endothelial cell monolayers. J Appl Physiol. 1990;69:1599-606.

32. Schaeffer RC, Gong F, Bitrick MS, Smith TL. Thrombin and bradykinin initiate discrete endothelial solute permeability mechanisms. Am J Physiol. 1993;264:1798-809.

33. Cirino G, Cicala C, Bucci MR, Sorrentino L, Maranganore JM, Stone SR. Thrombin functions as an inflammatory mediator through activation of its receptors. J Exp Med. 1996;183:821-7.

34. Huber-Lang M, Sarma JV, Zetoune FS, Rittirsch D, Neff TA, et al. Generation of C5a in the absence of C3: a new complement activation pathway. Nat Med.

2006;12:682-7.

35. Natbony SF, Phillips ME, Elias JM, Godfrey HP, Kaplan AP. Histologic studies of chronic idiopathic urticaria. J Allergy Clin Immunol. 1983;71:177-83.

36. Ying S, Kikuchi Y, Meng Q, Kay AB, Kaplan AP. TH1/ $\mathrm{TH} 2$ cytokines and inflammatory cells in skin biopsy specimens from patients with chronic idiopathic urticaria: comparison with the allergen-induced late-phase cutaneous reaction. J Allergy Clin Immunol.

2002; 109:694-700.

37. Kasperska-Zajac A, Sztylc J, Machura E, Jop G. Plasma IL6 concentration correlates with clinical disease activity and serum C-reactive protein concentration in chronic urticaria patients. Clin Exp Allergy. 2011;41:1386-91.

38. Tedeschi A, Asero R, Lorini M, Marzano AV, Cugno M. Plasma levels of matrix metalloproteinase-9 in chronic urticaria patients correlate with disease severity and Creactive protein but not with circulating histaminereleasing factors. Clin Exp Allergy. 2010;40:875-81.

39. Levi M, van der Poll T. Two-way interactions between inflammation and coagulation. Trends Cardiovasc Med. 2005;15:254-9.
40. Opal SM. Phylogenetic and functional relationships between coagulation and the innate immune response. Crit Care Med. 2000;28(Suppl):S77-80.

41. Chu AJ. Tissue factor mediates inflammation. Arch Biochem Biophys. 2005;440:123-32.

42. - Asero R. D-dimer: a biomarker for antihistamine-resistant chronic urticaria. J Allergy Clin Immunol. 2013;132:983-6.

This is the first study showing that the activation of coagulation cascade may be used as a biomarker for a specific subset of patients with chronic spontaneous urticaria.

43. Rabelo-Filardi R, Daltro-Oliveira R, Campos RA. Parameters associated with chronic spontaneous urticaria duration and severity: a systematic review. Int Arch Allergy Immunol. 2013;161:197-204.

44. - Asero R. Plasma D-dimer levels and clinical response to ciclosporin in severe chronic spontaneous urticaria. J Allergy Clin Immunol 2014 (e-pub ahead of print). A study confirming the possible clinical usefulness of the activation of the coagulation as a biomarker of more severe cases of chronic spontaneous urticaria.

45. Kasperska-Zajac A. Acute-phase response in chronic urticaria. J Eur Acad Dermatol Venereol. 2012;26:665-72.

46. Marzano AV, Tedeschi A, Fanoni D, Bonanni E, Venegoni L, Berti E, et al. Activation of blood coagulation in bullous pemphigoid: role of eosinophils, and local and systemic implications. Br J Dermatol. 2009;160:266-72.

47. Takahagi S, Mihara S, Iwamoto K, Morioke S, Okabe T, Kameyoshi Y, et al. Coagulation/fibrinolysis and inflammation markers are associated with disease activity in patients with chronic urticaria. Allergy. 2010;65:649-56.

48. Parslew R, Pryce D, Ashworth J. Friedmann PS Warfarin treatment of chronic idiopathic urticaria and angiooedema. Clin Exp Allergy. 2000;30:1161-5.

49. Meyer-De Schmid JJ, Neuman A. Treatment of chronic urticaria with heparin. Bull Soc Fr Dermatol Syphiligr. 1952;59:286-7.

50. Chua SL, Gibbs S. Chronic urticaria responding to subcutaneous heparin sodium. Br J Dermatol. 2005; 153:216-7.

51. Spring P, Angelillo-Scherrer A, Bigliardi P. Chronic idiopathic urticaria successfully treated by anticoagulant drugs. Eur J Dermatol. 2012;22:788-90.

52. Asero R, Tedeschi A, Cugno M. Heparin and tranexamic acid therapy may be effective in treatment-resistant chronic urticaria with elevated ddimer: a pilot study. Int Arch Allergy Immunol. 2010;152:384-9.

53. Tant D. Tranexamic acid in chronic urticaria. Br Med J. 1979;1:266.

54. Laurberg G. Tranexamic acid (Cyklokapron) in chronic urticaria: a double-blind study. Acta Derm Venereol. 1977;57:369-70.

55. Takahagi S, Shindo H, Watanabe M, Kameyoshi Y, Hide M. Refractory chronic urticaria treated effectively with the protease inhibitors, nafamostat mesilate and 
camostat mesilate. Acta Derm Venereol. 2010;90:4256.

56. Yang JW, Han BG, Kim BR, Lee YH, Kim YS, Yu JM, et al. Superior outcome of nafamostat mesilate as an anticoagulant in patients undergoing maintenance hemodialysis with intracerebral hemorrhage. Ren Fail. 2009;31:668-75.
57. Yalcin AD, Celik B, Gumuslu S. D-dimer levels drecreased in severe allergic asthma and chronic urticaria patients with the omalizumab treatment. Expert Opin Biol Ther. 2014;14:283-6.

An interesting study showing how the coagulation cascade activation parallels disease severity in chronic spontaneous urticarial. 